\title{
Insomnia in North Korean Refugees: Association with Depression and Post-Traumatic Stress Symptoms
}

\author{
Yu-Jin G. Lee ${ }^{1}$, Jin Yong Jun², Yu Jin Lee ${ }^{3}$, Juhyun Park ${ }^{3}$, Soohyun Kim³, \\ So Hee Lee ${ }^{4}$, So Young Yư , and Seog Ju Kim ${ }^{3,5,6}$ 凶 \\ 1'Department of Psychiatry, Seoul Metropolitan Eunpyeong Hospital, Seoul, Republic of Korea \\ 2Department of Psychiatry, Seoul National Hospital, Seoul, Republic of Korea \\ ${ }^{3}$ Department of Psychiatry, Seoul National University Hospital, Seoul, Republic of Korea \\ ${ }^{4}$ Department of Psychiatry, National Medical Center, Seoul, Republic of Korea \\ ${ }^{5}$ Center for Medicine and Korean Reunification, Seoul National University of College of Medicine, Seoul, Republic of Korea \\ ${ }^{6}$ Department of Psychiatry, Samsung Medical Center, Sungkyunkwan University School of Medicine, Seoul, Republic of Korea
}

Objective We investigated the prevalence of insomnia and its clinical characteristics in North Korean refugees.

Methods North Korean refugees living in South Korea (48 males, 129 females; mean age 38.22 \pm 12.24 years) and South Koreans (112 males, 203 females; mean age 39.48 \pm 10.32 years) completed the following questionnaires: the Self-reported Questionnaire on Insomnia, Center for Epidemiological Studies-Depression Scale (CES-D), Trauma Exposure Check List for North Korean Refugees, and the Impact of Event Scale-Revised (IES-R).

Results North Korean refugees had insomnia more often than South Koreans did (38.42\% vs. 8.89\%). Depression combined with insomnia was also more prevalent in North Korean refugees (28.25\% vs. 3.17\%). Compared with South Koreans with insomnia, North Korean refugees with insomnia showed higher CES-D scores. The North Korean refugees with insomnia had experienced a larger number of traumatic events, and had higher CES-D and IES-R scores compared to North Korean refugees without insomnia. Insomnia in North Korean refugees was also associated with the presence of significant depressive and post-traumatic stress disorder (PTSD) symptoms.

Conclusion Insomnia was common in North Korean refugees and was closely associated with depressive and PTSD symptoms. Our study suggests that complaints of insomnia may indicate more severe psychopathology, especially in refugees.

Psychiatry Investig 2016;13(1):67-73

Key Words North Korean refugee, Insomnia, Depression, Post-traumatic stress disorder.

\section{INTRODUCTION}

According to the 2012 report of the United Nations High Commissioner for Refugees (UNHCR), there were 15.4 million refugees worldwide. Besides the inevitable socioeconomic and cultural transitions during immigration, ${ }^{1}$ refugees commonly experience traumatic or stressful events including imprisonment, violence, torture, and exile. These experiences and the stress of acculturation to a new environment make

Received: January 13, 2015 Revised: February 22, 2015

Accepted: April 15, 2015 Available online: October 27, 2015

$\triangle$ Correspondence: Seog Ju Kim, MD, PhD

Department of Psychiatry, Samsung Medical Center, Sungkyunkwan University School of Medicine, 81 Irwon-ro, Gangnam-gu, Seoul 06351, Republic of Korea Tel: +82-2-3410-3583, Fax: +82-2-3410-0050, E-mail: ksj7126@skku.edu

(a) This is an Open Access article distributed under the terms of the Creative Commons Attribution Non-Commercial License (http://creativecommons.org/licenses/by$\mathrm{nc} / 3.0$ ) which permits unrestricted non-commercial use, distribution, and reproduction in any medium, provided the original work is properly cited. refugees highly vulnerable to psychological symptoms. ${ }^{2}$

North Korean refugees are individuals who left North Korea to escape starvation or political repression in their country. Approximately 26,000 North Korean refugees had settled in South Korea by February 2014. North Korean refugees have commonly experienced traumatic events such as torture, violence, rape, human trafficking, imprisonment, and witnessing death by public execution, starvation, or shooting. ${ }^{3,4} \mathrm{Be}-$ fore settling in South Korea, most North Korean refugees have felt extreme insecurity about the fear of arrest and deportation back to North Korea. Even after their arrival in South Korea, they often experience diminished socioeconomic status, culture shock, prejudice, and financial difficulties. ${ }^{5}$ As a consequence of various traumatic and stressful experiences, North Korean refugees are at high risk of psychiatric symptoms. ${ }^{6,7}$

Sleep disturbances, especially insomnia, have been proposed to be closely related to stressful or traumatic experiences. ${ }^{8}$ In- 
somnia is a very frequent symptom of depressive disorder or post-traumatic stress disorder (PTSD), which are common in refugees. ${ }^{9,10}$ However, studies on insomnia in refugees are limited. One study reported a high incidence (44\%) of insomnia in internally displaced people, ${ }^{8}$ which was closely related to war-related stress and depressive mood. However, insomnia in other refugee populations such as North Koreans has not been investigated.

In the present study, we examined the prevalence and clinical characteristics of insomnia in North Korean refugees. To the best of our knowledge, this is the first study regarding insomnia in North Korean refugees. We hypothesized that insomnia would be more common in North Korean refugees than in South Koreans and that North Korean refugees' insomnia would be closely related to psychiatric symptoms and prior traumatic experiences.

\section{METHODS}

\section{Subjects}

A total of 177 North Korean refugees living in South Korea (48 males, 129 females; $38.22 \pm 12.24$ years of age) and 315 native South Koreans (112 males, 203 females; 39.48 \pm 10.32 years of age) were recruited by advertisements and participated in the current study.

The mean time between the first departure from North Korea and study participation among North Korean refugees was $7.13 \pm 3.86$ years. The mean time spent in countries other than North or South Korea during defection was 2.65 \pm 3.69 years, and the mean time of settlement in South Korea was $4.09 \pm 2.57$ years. The study protocol was approved by the Institutional Review Board of Myeongji Hospital, Kwandong University. Following a complete description of the study, written informed consent was obtained from all participants.

\section{Insomnia assessment}

The presence or absence of insomnia was determined through a self-reported questionnaire regarding sleep experiences over the previous month including 1) difficulty initiating sleep, 2) difficulty maintaining sleep, and 3) early awakening and difficulty resuming sleep. ${ }^{11,12}$ Based on the diagnostic criteria of the International Classification of Diseases-10 (ICD10), participants experiencing at least one of the three types of insomnia (initial, maintenance, and terminal) $\geq 3$ /week were classified as having significant insomnia.

\section{Assessments of depressive symptoms}

To measure depressive symptoms, the Korean version of the Center for Epidemiological Studies-Depression Scale (CES-D) was administered to both North Korean refugees and
South Korean participants. ${ }^{13}$ Because the Korean version tends to be scored higher than the comparable English version, despite its high reliability and validity, subjects with a CES-D score of 21 or greater were defined as having depressive symptoms based on a previous study using the Korean version of CES-D. ${ }^{13}$

\section{Assessments of traumatic events and PTSD symptoms}

The Trauma Exposure Check List for North Korean Refugees was used for assessing previous exposures to traumatic events in North Korea. ${ }^{14,15}$ The self-report instrument inquires whether respondents were exposed to any of the 13 types of traumatic events during residency in North Korea or to any of 16 types of traumatic events during defection prior to their arrival in South Korea. The traumatic events in the questionnaire include torture, severe battery, life-threatening starvation/cold/accidents, rape, human trafficking, arrest, imprisonment, and witnessing killing. The North Korean refugees in the present study had experienced a mean of $6.73 \pm 4.87$ traumatic events.

The Impact of Event Scale-Revised (IES-R) was used to assess PTSD symptoms in North Korean refugees. The IES-R consists of 22 questions assessing the subjective response to a specific traumatic event in terms of the typical PTSD symptoms, i.e., intrusion (re-experience), avoidance, and hyperarousal. ${ }^{16}$ Five additional questions were added to the original version of IES, ${ }^{17}$ as it did not measure hyperarousal. In previous research, ${ }^{18}$ subjects with an IES-R score of 25 or greater were defined as having significant PTSD symptoms. The Trauma Exposure Check List and IES-R were administered only to North Korean refugees and not to South Koreans.

\section{Statistical analyses}

Group differences in demographic variables involving continuous data were evaluated using independent t-tests or ANOVA. Between-group comparisons involving categorical data were assessed using the chi-square test. Additionally, ANCOVA with age and gender as covariates was performed to examine between-group differences. To investigate the determinants of insomnia in North Korean refugees, multiple logistic regression analysis (dependent variable: presence/absence of significant insomnia; independent variables: age, gender, number of previous traumatic events, CES-D and IES-R scores) was also performed. A two-tailed alpha of $<0.05$ was considered to indicate statistical significance, and SPSS version 16.0 for Windows software was used for all computations. 
Table 1. Demographic and clinical characteristics of subjects

\begin{tabular}{|c|c|c|c|c|}
\hline & $\begin{array}{l}\text { North Korean refugees } \\
\qquad(\mathrm{N}=177)\end{array}$ & $\begin{array}{l}\text { South Koreans } \\
\qquad(\mathrm{N}=315)\end{array}$ & $\operatorname{tor} \chi^{2}$ & $\mathrm{p}$ \\
\hline & Mean \pm SD $(\mathrm{N}, \%)$ & Mean \pm SD $(\mathrm{N}, \%)$ & & \\
\hline Age & $38.22 \pm 12.24$ & $39.48 \pm 10.32$ & $\mathrm{t}=1.16$ & 0.25 \\
\hline \multicolumn{5}{|l|}{ Gender } \\
\hline Male & $48(27.12)$ & $112(35.56)$ & $\chi^{2}=3.3$ & 0.07 \\
\hline Female & $129(72.88)$ & $203(64.44)$ & & \\
\hline \multicolumn{5}{|l|}{ Depression } \\
\hline CES-D score & $21.00 \pm 12.51$ & $9.44 \pm 8.98$ & $\mathrm{t}=10.83$ & $<0.001$ \\
\hline Subjects with depressive symptoms (CES-D score $\geq 21$ ) & $82(46.33)$ & $32(10.16)$ & $\chi^{2}=81.26$ & $<0.001$ \\
\hline \multicolumn{5}{|l|}{ PTSD } \\
\hline Number of traumatic experiences & $6.73 \pm 4.87$ & - & & \\
\hline \multicolumn{5}{|l|}{ IES-R score } \\
\hline Intrusion & $8.21 \pm 7.99$ & - & & \\
\hline Avoidance & $8.76 \pm 7.91$ & - & & \\
\hline Hyperarousal & $6.09 \pm 6.45$ & - & & \\
\hline Total score & $23.06 \pm 21.16$ & - & & \\
\hline Subjects with significant PTSD symptoms (IES score $\geq 25$ ) & $71(40.11)$ & - & & \\
\hline \multicolumn{5}{|l|}{ Subjects with insomnia } \\
\hline Initial insomnia & $55(31.07)$ & $23(7.30)$ & $\chi^{2}=46.24$ & $<0.001$ \\
\hline Maintenance insomnia & $53(29.94)$ & $22(6.98)$ & $\chi^{2}=44.48$ & $<0.001$ \\
\hline Terminal insomnia & $43(24.29)$ & $12(3.81)$ & $\chi^{2}=45.85$ & $<0.001$ \\
\hline Any significant insomnia & $68(38.42)$ & $28(8.89)$ & $\chi^{2}=61.05$ & $<0.001$ \\
\hline Insomnia with depressive symptoms & $50(28.25)$ & $10(3.17)$ & $\chi^{2}=64.22$ & $<0.001$ \\
\hline Insomnia with PTSD symptoms & $45(25.42)$ & - & & \\
\hline
\end{tabular}

PTSD: post-traumatic stress disorder, CES-D: Center for Epidemiological Studies-Depression Scale, IES-R: Impact of Event Scale-Revised

\section{RESULTS}

\section{Comparison between North Korean refugees and South Koreans}

The demographic and clinical data are presented in Table 1. Differences in age between North Korean refugees and South Koreans were not significant, although the proportion of females was higher in North Korean refugees $\left(\chi^{2}=3.3, p=0.07\right)$. CES-D scores of North Korean refugees were higher compared with those of South Koreans ( $t=10.83, \mathrm{p}<0.001)$, and significant depressive symptoms were also more common in North Korean refugees than in South Koreans ( $46.33 \%$ vs. $10.16 \%, \chi^{2}=81.26, p<0.001$ ). Clinically significant insomnia was more common in North Korean refugees than in South Koreans $\left(38.42 \%\right.$ vs. $\left.8.89 \%, \chi^{2}=61.05, p<0.001\right)$, and this was true of all three types of insomnia (initial, maintenance and terminal) $\left(\chi^{2}=46.24, \mathrm{p}<0.001 ; \chi^{2}=44.48, \mathrm{p}<0.001 ; \chi^{2}=45.85\right.$, $\mathrm{p}<0.001$, respectively). Furthermore, North Koreans refugees were more likely to show symptoms of both depression and insomnia ( $28.25 \%$ vs. $\left.3.17 \%, \chi^{2}=64.22, \mathrm{p}<0.001\right)$. Among North Korean refugees, 71 participants (40.11\%) had significant PTSD symptoms, and 45 subjects (25.42\%) had both PTSD and insomnia.

In order to find out the most common type of trauma inducing PTSD symptoms in North Korean refugees, backward multiple regression model was conducted (dependent variables: IES-R score, independent variables; 29 types of traumatic events for North Korean refugees). Four events significantly and independently predicted higher IES-R score; 1) lifethreatening starvation in North Korea (beta $=0.22, \mathrm{p}<0.001$ ), which was experienced by $46.33 \%$ of refugees, 2 ) life-threatening accidents in North Korea (beta $=0.26, \mathrm{p}<0.001$ ), which was experienced by $18.08 \%$ of refugees, 3 ) severe battery during defection (beta $=0.17, \mathrm{p}<0.01$ ), which was experienced by $20.90 \%$ of refugees, and 4 ) human trafficking during defection (beta $=0.32, \mathrm{p}<0.001$ ), which was experienced by $16.38 \%$ of refugees. 


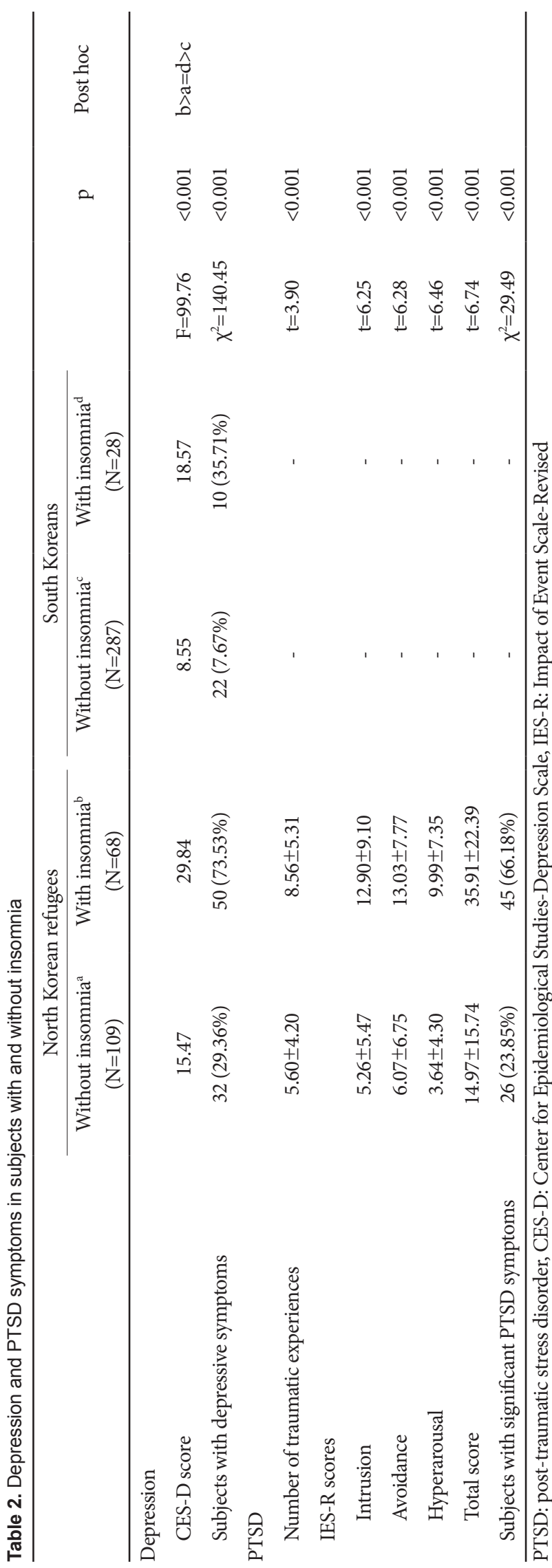

\section{Depression and PTSD symptoms in subjects with and without insomnia}

When study subjects were divided into four groups based on origin and insomnia (i.e., North Korean refugees without and North Korean refugees with insomnia, South Koreans without and South Koreans with insomnia), the CES-D scores $(\mathrm{F}=99.76, \mathrm{p}<0.001)$ and the proportion of subjects with depressive symptoms $\left(\chi^{2}=140.45, \mathrm{p}<0.001\right)$ were significantly different among the groups (Table 2). Post hoc analysis showed that the CES-D scores of North Korean refugees with insomnia were significantly higher than those for the other three groups, and that the CES-D scores of South Koreans without insomnia were significantly lower than those of the other groups. North Korean refugees with insomnia had experienced a larger number of traumatic events, on average $(t=3.90$, $\mathrm{p}<0.001)$ and had higher IES-R scores $(\mathrm{t}=6.74, \mathrm{p}<0.001)$ compared with those without insomnia. North Korean refugees with insomnia were more likely to have clinically significant PTSD symptoms than those were without insomnia $\left(66.18 \%\right.$ vs. $\left.23.85 \%, \chi^{2}=29.49, \mathrm{p}<0.001\right)$. When age and gender were controlled, similar results were observed.

\section{Insomnia and PTSD symptoms in subjects with and without depression}

Study subjects were divided into four groups based on origin and depression (i.e., North Korean refugees without and North Korean refugees with depression, South Koreans without and South Koreans with depression) (Table 3). The proportion of subjects with insomnia was significantly different $\left(\chi^{2}=109.17, \mathrm{p}<0.001\right)$ among groups. Clinically significant insomnia was more common in North Korean refugees with depression than in North Korean refugees without depression and South Koreans with depression. South Koreans with depression were more likely to have insomnia than were South Koreans without depression, and North Korean refugees with depressive symptoms had experienced a larger number of traumatic events $(\mathrm{t}=4.67, \mathrm{p}<0.001)$ and showed higher IES-R scores $(\mathrm{t}=8.74, \mathrm{p}<0.001)$ than non-depressive North Korean refugees. North Korean refugees with depression more often had clinically significant PTSD symptoms compared with those without depression $\left(\chi^{2}=41.05, \mathrm{p}<0.001\right)$.

\section{Insomnia and depression in subjects with and without PTSD symptoms}

When North Korean refugees were divided into those with and those without PTSD symptoms, clinically significant insomnia $\left(\chi^{2}=29.49, \mathrm{p}<0.001\right)$ and depressive symptoms $\left(\chi^{2}=\right.$ 45.90, $\mathrm{p}<0.001)$ were more common in those with PTSD than those without it (Table 4), and CES-D scores were higher in North Korean refugees with PTSD than in those without it. 


\section{Determinants of insomnia in North Korean refugees}

Multiple logistic regression analysis was performed to investigate the determinants of insomnia in North Korean refugees. In the multiple logistic regression model (dependent variable: presence/absence of clinically meaningful insomnia; independent variables: age, gender, number of previous traumatic events, CES-D score, and IES-R score), only the CES-D score significantly predicted the presence of insomnia (Wald= 18.91, $\mathrm{p}<0.001)$. When insomnia was classified into three types (initial, maintenance, and terminal insomnia), the CESD score significantly predicted initial (Wald $=12.44, \mathrm{p}<0.001$ ), maintenance (Wald $=12.49, \mathrm{p}<0.001$ ), and terminal insomnia (Wald=9.43, $\mathrm{p}<0.01$ ) insomnia, whereas IES-R score predicted only maintenance (Wald $=5.19, \mathrm{p}=0.02$ ) and terminal (Wald=
3.63, $\mathrm{p}=0.05)$ insomnia.

When North Korean refugees were divided into 4 groups based on the presence/absence of significant depressive or PTSD symptoms, seventy-nine (44.63\%) had neither depressive nor PTSD symptoms. Twenty-seven (15.25\%) had only depressive symptoms without significant PTSD symptoms, while sixteen (9.04\%) had only PTSD symptoms without significant depressive symptoms. Fifty-five (31.07\%) had both depressive and PTSD symptoms. The proportion of subjects with insomnia was significantly different $\left(\chi^{2}=42.63, \mathrm{p}<0.001\right)$ among groups. The proportion of significant insomnia was higher in those with both depression and PTSD ( $n=39,70.91 \%)$ than other 3 groups. The clinically significant insomnia was less common in those without depression and PTSD $(n=16$,

Table 3. Insomnia and PTSD symptoms in subjects with and without depression

\begin{tabular}{|c|c|c|c|c|c|c|}
\hline & \multicolumn{2}{|c|}{ North Korean refugees } & \multicolumn{2}{|c|}{ South Koreans } & \multirow[b]{2}{*}{$\chi^{2}$ or $\mathrm{t}$} & \multirow[b]{2}{*}{$\mathrm{p}$} \\
\hline & $\begin{array}{l}\text { Without depression } \\
\qquad(\mathrm{N}=95)\end{array}$ & $\begin{array}{l}\text { With depression } \\
\qquad(\mathrm{N}=82)\end{array}$ & $\begin{array}{l}\text { Without depression } \\
\qquad(\mathrm{N}=283)\end{array}$ & $\begin{array}{l}\text { With depression } \\
\qquad(\mathrm{N}=32)\end{array}$ & & \\
\hline \multicolumn{7}{|l|}{ Insomnia } \\
\hline Initial insomnia & $15(15.79 \%)$ & $40(48.78 \%)$ & $15(5.30 \%)$ & $8(25.00 \%)$ & $\chi^{2}=88.11$ & $<0.001$ \\
\hline Maintenance insomnia & $11(11.58 \%)$ & $42(51.22 \%)$ & $14(4.95 \%)$ & $8(25.00 \%)$ & $\chi^{2}=103.89$ & $<0.001$ \\
\hline Terminal insomnia & $9(9.47 \%)$ & $34(41.46 \%)$ & $6(2.12 \%)$ & $6(18.75 \%)$ & $x^{2}=97.14$ & $<0.001$ \\
\hline Any significant insomnia & $19(20.00 \%)$ & $50(60.98 \%)$ & $22(7.77 \%)$ & $12(37.50 \%)$ & $\chi^{2}=109.17$ & $<0.001$ \\
\hline \multicolumn{7}{|l|}{ PTSD } \\
\hline $\begin{array}{l}\text { Number of traumatic } \\
\text { experiences }\end{array}$ & $5.12 \pm 4.02$ & $8.50 \pm 5.18$ & - & - & $\mathrm{t}=4.67$ & $<0.001$ \\
\hline \multicolumn{7}{|l|}{ IES-R scores } \\
\hline Intrusion & $4.20 \pm 4.78$ & $12.91 \pm 8.46$ & - & - & $\mathrm{t}=8.23$ & $<0.001$ \\
\hline Avoidance & $5.11 \pm 6.11$ & $13.05 \pm 7.64$ & - & - & $\mathrm{t}=7.53$ & $<0.001$ \\
\hline Hyperarousal & $2.73 \pm 3.38$ & $10.04 \pm 6.95$ & - & - & $\mathrm{t}=8.64$ & $<0.001$ \\
\hline Total score & $12.03 \pm 13.23$ & $36.00 \pm 21.45$ & - & - & $\mathrm{t}=8.74$ & $<0.001$ \\
\hline $\begin{array}{l}\text { Subjects with significant } \\
\text { PTSD symptoms }\end{array}$ & $16(16.84 \%)$ & $55(67.07 \%)$ & - & - & $\chi^{2}=41.05$ & $<0.001$ \\
\hline
\end{tabular}

PTSD: post-traumatic stress disorder, IES-R: Impact of Event Scale-Revised

Table 4. Insomnia and depression in subjects with and without PTSD symptoms

\begin{tabular}{|c|c|c|c|c|}
\hline & $\begin{array}{l}\text { NK refugees without PTSD } \\
\text { symptoms }(\mathrm{N}=106)\end{array}$ & $\begin{array}{l}\text { NK refugees with PTSD } \\
\text { symptoms }(\mathrm{N}=71)\end{array}$ & $\chi^{2}$ or $t$ & $\mathrm{p}$ \\
\hline \multicolumn{5}{|l|}{ Insomnia } \\
\hline Initial insomnia & $19(17.92 \%)$ & $36(50.70 \%)$ & $\chi^{2}=19.83$ & $<0.001$ \\
\hline Maintenance insomnia & $14(13.21 \%)$ & $39(54.93 \%)$ & $\chi^{2}=33.32$ & $<0.001$ \\
\hline Terminal insomnia & $11(10.38 \%)$ & $32(45.07 \%)$ & $\chi^{2}=25.97$ & $<0.001$ \\
\hline Any significant insomnia & $23(21.70 \%)$ & $45(63.38 \%)$ & $x^{2}=29.49$ & $<0.001$ \\
\hline \multicolumn{5}{|l|}{ Depression } \\
\hline CES-D score & $15.27 \pm 9.47$ & $29.38 \pm 11.77$ & $\mathrm{t}=8.43$ & $<0.001$ \\
\hline Subjects with depressive symptoms & $26(24.53 \%)$ & $55(77.46 \%)$ & $\chi^{2}=45.90$ & $<0.001$ \\
\hline
\end{tabular}


$15.19 \%)$ than those with only depression $(n=16,40.74 \%)$ or those with only PTSD ( $n=6,37.50 \%)$.

The time of settlement in South Korea did not significantly correlate with IES-R or with CES-D score. There was no difference of time of settlement in South Korea between those with and without clinically significant insomnia. When divided into those who settled in South Korea within 3 years and those whose settlement was more than 3 years, there were no significant differences in IES-R score, CES-D score and the proportion of insomnia between groups.

\section{DISCUSSION}

The present study investigated the prevalence of insomnia and its clinical characteristics in North Korean refugees. Insomnia was more common in North Korean refugees than in South Koreans. Among North Korean refugees, those with insomnia were more likely to have depressive and PTSD symptoms. When insomnia was present, North Korean refugees were more likely to have depression compared with South Koreans.

In agreement with our primary hypothesis, insomnia was significantly more common in North Korean refugees than in native South Koreans. Although few studies on insomnia among refugees have been conducted, one previous study reported that the incidence of insomnia in a refugee group was $41.4 \%,{ }^{8}$ similar to $38.4 \%$ in the current study. A higher incidence of all subtypes of insomnia (i.e., initial, maintenance, and terminal insomnia) was found among North Korean refugees than among South Koreans. Our study suggests that the previous experiences and/or the current situation of refugees may be related to elevated nocturnal arousal throughout the night.

Our second hypothesis was that insomnia in North Korean refugees was closely related to psychiatric symptoms. As in prior studies on the mental health of North Korean refugees, ${ }^{19,20}$ these refugees exhibited depressive symptoms more often than did native South Koreans. The incidence of combined insomnia and depression was also higher in North Korean refugees. Insomnia was more strongly related to depression in North Korean refugees than in South Koreans, and insomnia was correlated with significant depressive symptoms among these refugees. The findings in the current study suggest insomnia in North Korean refugees is likely to be comorbid with or secondary to depression rather than independent of it.

Additionally, insomnia among North Korean refugees was associated with traumatic experiences or PTSD symptoms. Prior studies on North Korean refugees have reported a very high prevalence of PTSD, ${ }^{21}$ as many North Korean refugees have been exposed to traumatic life events. ${ }^{22}$ In the current study, North Korean refugees with insomnia were more likely to have experienced traumatic events and were more likely to show symptoms of intrusion, avoidance, and hyperarousal compared with those without insomnia. Similarly, North Korean refugees with PTSD symptoms were more likely to have insomnia than were those without. Our study suggests that the refugee insomnia may develop due to traumatic experiences and may be associated with PTSD.

The current study suggests that refugees' insomnia may indicate psychiatric disorders such as depressive disorder or PTSD. Many refugees tend to complain more about their somatic or physiological symptoms than about mental or psychological symptoms. ${ }^{23,24}$ North Korean refugees have also been reported to have tendencies toward somatization and alexithymia, which are related to psychiatric problems. ${ }^{14,15}$ Furthermore, refugees usually come from countries where the concept of psychiatric disorders is unfamiliar or stigmatized, as is the case in North Korea. ${ }^{4}$ Some items of questionnaires describing more abstract theme may be misunderstood by North Korean refugees. Some item of CES-D regarding social isolation or comparison with others may reflect the reality of prejudice commonly experienced by North Korean refugees. However, insomnia is a definite symptom that can hardly be misunderstood. Therefore, many refugees may complain only of insomnia without voluntarily admitting their psychological distress. However, in the current study, depression and PTSD were very common in refugees with insomnia. Clinicians in sleep clinics should pay attention to masked depression or PTSD, even when refugees complain only of insomnia without reporting other psychiatric symptoms.

The present study had several limitations. First, the PTSD symptoms of South Koreans could not be assessed, as the traumatic events most North Korean refugees underwent were rarely experienced by ordinary South Koreans. A previous study reported that the prevalence of PTSD was only $1.7 \%$ in South Korea, ${ }^{25}$ whereas that among North Korean refugees was as high as $56 \% .^{21}$ The prevalence of PTSD in refugees resettled in western countries were reported as $9 \%$ in a review. ${ }^{26}$ Secondly, we could not evaluate changes in insomnia and other psychiatric symptoms longitudinally. Whether the insomnia pre-dated or followed the onset of depression or PTSD in North Korean refugees remains unclear. Longitudinal study was also needed for investigating the change of PTSD symptoms, depression and insomnia during early settlement period in South Korea. Thirdly, other psychiatric problem including suicidal idea or substance abuse, which are closely related to sleep or insomnia was not assessed in the current study. Finally, assessments of insomnia, depression, and PTSD were all based on self-report. Structured psychiatric diagnostic interviews and objective measures of sleep such as polysom- 
nography might improve the strength of this study.

In the current study, we investigated insomnia among North Korean refugees and found that it was very common in this group. Insomnia was related to a greater likelihood of psychiatric symptoms such as depression and PTSD. Our study suggests that sleep physicians should pay attention to hidden or underdiagnosed psychiatric disorders when refugees complain of insomnia.

\section{Acknowledgments}

This study was supported by grant No. 0420120380 from the Seoul National University Hospital (SNUH) Research Fund and a National Research Foundation of Korea (NRF) grant funded by the Korean government (MEST) (No. 2013R1A1A2A10007021).

\section{REFERENCES}

1. Bhugra D. Migration, distress and cultural identity. Br Med Bull 2004; 69:129-141.

2. Steel Z, Chey T, Silove D, Marnane C, Bryant RA, van Ommeren M. Association of torture and other potentially traumatic events with mental health outcomes among populations exposed to mass conflict and displacement: a systematic review and meta-analysis. JAMA 2009; 302:537-549.

3. Jeon WT, Yu SE, Cho YA, Eom JS. Traumatic experiences and mental health of North Korean refugees in South Korea. Psychiatry Investig 2008;5:213-220.

4. Park YS, Park SM, Jun JY, Kim SJ. Psychiatry in former socialist countries: implications for North Korean psychiatry. Psychiatry Investig 2014;11:363-370.

5. Yu SE, Eom JS, Jeon WT. The factors affecting the development of national identity as South Korean in North Korean refugees living in South Korea. Psychiatry Investig 2012;9:209-216.

6. Kim HK, Lee OJ. A phenomenological study on the experience of North Korean refugees. Nurs Sci Q 2009;22:85-88.

7. Lee YM, Shin OJ, Lim MH. The psychological problems of North Korean adolescent refugees living in South Korea. Psychiatry Investig 2012;9:217-222.

8. Basishvili T, Eliozishvili M, Maisuradze L, Lortkipanidze N, Nachkebia $\mathrm{N}$, Oniani T, et al. Insomnia in a displaced population is related to warassociated remembered stress. Stress Health 2012;28:186-192.

9. Staner L. Comorbidity of insomnia and depression. Sleep Med Rev 2010;14:35-46.

10. McLay RN, Klam WP, Volkert SL. Insomnia is the most commonly reported symptom and predicts other symptoms of post-traumatic stress disorder in U.S. service members returning from military deployments.
Mil Med 2010;175:759-762.

11. Lee YJ, Cho SJ, Cho IH, Jang JH, Kim SJ. The relationship between psychotic-like experiences and sleep disturbances in adolescents. Sleep Med 2012;13:1021-1027.

12. Lee S, Kim SJ, Park JE, Cho SJ, Cho IH, Lee YJ. Biogenetic temperament and character in insomnia and depression. J Psychosom Res 2012;72:383-387.

13. Cho MJ, Kim KH. Use of the Center for Epidemiologic Studies Depression (CES-D) scale in Korea. J Nerv Ment Dis 1998;186:304-310.

14. Jun JY, Lee YJ, Lee SH, Yoo SY, Song J, Kim SJ. Association between defense mechanisms and psychiatric symptoms in North Korean Refugees. Compr Psychiatry 2015;56:179-187.

15. Park J, Jun JY, Lee YJ, Kim S, Lee SH, Yoo SY, et al. The association between alexithymia and posttraumatic stress symptoms following multiple exposures to traumatic events in North Korean refugees. J Psychosom Res 2015;78:77-81.

16. Weiss DS, Marmar CR. The Impact of Event Scale-revised. In: Wilson JP, Keane TM, Editors. Assessing Psychological Trauma and PTSD. New York: Guilford Press, 1997, p. 399-411.

17. Horowitz M, Wilner N, Alvarez W. Impact of event scale: a measure of subjective stress. Psychosom Med 1979;41:209-218.

18. Eun HJ, Kwon TW, Lee SM, Kim TH, Choi MR, Cho SJ. A study on reliability and validity of the Korean version of impact of event scalerevised. J Korean Neuropsychiatr Assoc 2005;44:1015-1017.

19. Kim HH, Lee YJ, Kim HK, Kim JE, Kim SJ, Bae SM, et al. Prevalence and correlates of psychiatric symptoms in North Korean defectors. Psychiatry Investig 2011;8:179-185.

20. Jeon BH, Kim MD, Hong SC, Kim NR, Lee CI, Kwak YS, et al. Prevalence and correlates of depressive symptoms among North Korean defectors living in South Korea for more than one year. Psychiatry Investig 2009;6:122-130.

21. Lee Y, Lee MK, Chun KH, Lee YK, Yoon SJ. Trauma experience of North Korean refugees in China. Am J Prev Med 2001;20:225-229.

22. Jeon W, Hong C, Lee C, Kim DK, Han M, Min S. Correlation between traumatic events and posttraumatic stress disorder among North Korean defectors in South Korea. J Trauma Stress 2005;18:147-154.

23. Andreski P, Chilcoat H, Breslau N. Post-traumatic stress disorder and somatization symptoms: a prospective study. Psychiatry Res 1998;79: 131-138.

24. Westermeyer J, Bouafuely M, Neider J, Callies A. Somatization among refugees: an epidemiologic study. Psychosomatics 1989;30:34-43.

25. Jeon HJ, Suh T, Lee HJ, Hahm BJ, Lee JY, Cho SJ, et al. Partial versus full PTSD in the Korean community: prevalence, duration, correlates, comorbidity, and dysfunctions. Depress Anxiety 2007;24:577-585.

26. Fazel M, Wheeler J, Danesh J. Prevalence of serious mental disorder in 7000 refugees resettled in western countries: a systematic review. Lancet 2005;365:1309-1314. 